\title{
Boosting School Administrator Confidence when Evaluating Special Educators through District Support and Training
}

\author{
Corrine M. Aramburo \\ Janelle Rodl \\ San Francisco State University, USA
}

\begin{abstract}
This current study is an exploratory, secondary data analysis of a survey assessing training, district support, and confidence of school administrators when it comes to special education teacher evaluation. The present study specifically examines (a) if the influence of district training regarding special education teachers influences the confidence of school administrators to evaluate and observe special education teachers, (b) if administrators with a general education credential differ from administrators with a special education credential regarding the type of district support needed to better evaluate special education teachers; and (c) if possessing a special education credential influences an administrator's confidence when evaluating both general and special education teachers at their school site. Results indicated that district training regarding special education teacher evaluation increased administrator confidence and that administrators with general education credentials desired more district support overall than did their counterparts with a special education credential. The data also showed that administrators with a special education credential felt significantly more confident evaluating special education and general education teachers than did their counterparts from general education backgrounds. Implications for the field of special education evaluation and future directions are discussed.
\end{abstract}

Keywords: confidence, school administrators, special education teacher evaluation

In recent decades, the role of the school administrator (e.g., principal, vice principal, charter school director, and other instructional leaders) has undergone a dramatic shift. Formerly, school administrators were seen as the school disciplinarians and managers of teachers (Lynch, 2012) with little to no training in, or knowledge of, leadership skills or how to administer specialized programs (Monteith, 2000). Currently, school administrators are looked to as instructional leaders with growing responsibilities and complex roles (DiPaola \& Walther-Thomas, 2003; Hess \& Kelly, 2007; Lynch, 2012). Instructional leadership has multiple dimensions including promoting positive learning environments for all students, evaluating instructional programs and teachers, and developing systems for accountability in order to monitor student learning (DiPaola \& Walther-Thomas, 2003; Green, 2010; Duncan et al., 2011).

Integral to administrators' job functions as instructional leaders is the role of teacher evaluator. In an effort to standardize the field of teacher evaluation, a crop of new evaluation systems has emerged (Hallinger et al., 2013; Neumerski et al., 2018), including structured rubrics within observation-based systems (Neumerski et al., 2018). Under the structured rubric framework, principals are expected to utilize classroom observation data collected using their state or district's designated rubric to make executive decisions about their teaching staff (Cohen-Vogel \& Harrison, 2013). Administrators are expected to observe their teachers on numerous occasions throughout the school year while detailing a teacher's performance based on the rubric's definition of "high-quality" practices in various educational domains (Neumerski et al., 2018). Following an observation, principals are expected to engage in a post-observation conference to provide the teacher with on-going support, specific feedback on their instructional practices, and opportunities for growth and development (Grissom \& Youngs, 2016; Hill \& Grossman, 2013). 
School administrators are typically the instructional leaders for all teachers on their school sites, including special education teachers. It is often the school administrator who will perform evaluations of, make personnel decisions regarding, and offer support to the special educator; consequently, school administrators need to be well versed in the practices and development of special education teachers. School administrators should be able to recognize evidencebased practices and differentiate effective from ineffective special educators (Bays \& Crockett, 2007; Holdheide et al., 2010; Steinbrecher et al., 2015). Research suggests, however, that some school administrators have limited knowledge of special education, including evidence-based practices (Holdheide et al., 2010; Steinbrecher et al., 2015), and lack an understanding of special education teachers' various professional roles (Steinbrecher et al., 2015). This may be due in part to the fact that many school administrators advance through the general education teacher pipeline and do not have formal training or a background in special education (Bays \& Crockett, 2007).

This gap in professional knowledge is particularly problematic as it may adversely impact the evaluative process as it applies to special educators. When conducting direct observations of classroom practice for evaluative purposes, school administrators should be able to identify special education teachers' evidence-based instructional practices, make evaluative decisions, and offer feedback to the teacher. This process allows school administrators to communicate ways to help teachers improve their practice and to convey that the special educator's work is of importance (Bettini et al., 2015). Constructive feedback shows a concern for special educators and their students' progress, thus promoting a positive and supportive school environment (Vittek, 2015). Furthermore, feedback from evaluations given by school administrators has proven to be a vital component in stemming special educator attrition rates; that is, special education teachers who received feedback about their practices from school administrators experienced less burnout than special education teachers who did not receive feedback (Brunsting et al., 2014).

\section{Administrator Preparation Related to Special Education Teacher Evaluation}

Research suggests that school administrators do not receive adequate preparation for teacher evaluation generally, and receive very little, if any, preparation related to evaluating special education teachers specifically. In their analysis of 210 syllabi across 31 educational leadership preparation programs nationwide, Hess and Kelly (2007) found that the majority of these programs spent limited time training pre-service principals on how to evaluate teachers. Similarly, Duncan et al. (2011) conducted a survey of 106 Wyoming principals concerning their views about their administrative preparation programs and found that many of the principals identified supervision and evaluation as shortfalls. In-service principals have also reported little to no training in their administrative preparation courses on the teacher evaluation process, and that having some type of training during pre-service preparation would have made them more effective evaluators (Lawson \& Knollman, 2017).

Research on preparation related to supporting and evaluating special education teachers is extremely limited. According to Jacobs et al. (2004), administrative preparation programs rarely deliver information on the instructional needs of students with disabilities or how school administrators can handle these needs at their school sites. Furthermore, many administrative certification programs do not require special education coursework as this is not compulsory in most states (Bettini et al., 2015; Jacobs et al., 2004; Patterson et al., 2000; Steinbrecher et al., 2015). This would suggest that pre-service administrators who do not already have formal training or experience in special education have little opportunity to acquire special education knowledge that would enable them to better support special education teachers and their students. Angelle and Bilton (2009) found that when principals had even limited exposure to special education matters through formal coursework, they experienced significantly higher comfort levels handling special education issues than did those principals without formal coursework; yet, many school administrators do not have this opportunity (Westling et al., 2006).

If principals do not receive needed information during their preparation programs, the next logical source of professional development and in-service training would be the school district. School districts have the potential to be a rich training ground as they are equipped to consider contextual factors that influence school administrators' job tasks. Currently, it is unclear the extent to which districts offer professional development and training related to supporting and evaluating special education teachers. Duncan et al. (2011) found that many novice principals indicated the need for inservice professional development from their districts regarding teacher evaluation and reported that the amount of support provided by districts was limited. Rodl et al. (2018) surveyed over 900 school administrators in California and found that 61 percent of respondents felt they needed more support from their districts when it came to special education teacher evaluation, with close to half reporting the need for professional development.

Limited training opportunities may impact the extent to which administrators feel confident performing 
observations and evaluations of special education teachers. In their survey of elementary principals, Glowacki and Hackmann (2016) found that respondents who lacked formal coursework and a background in special education teaching felt less confident evaluating and providing feedback to special education teachers than to general education teachers. Respondents also reported the need to become more knowledgeable about special education best practices. Rodl et al. (2018) corroborated these findings in a survey of California school administrators; results indicated that school administrators with a special education teaching credential were significantly more confident evaluating special education teachers than were their peers without a special education credential, regardless of years of experience.

\section{Purpose of the Study}

As instructional leaders, school administrators have an important role in the development of special education teachers through observation, evaluation (Bays \& Crockett, 2007; Holdheide et al., 2010; Steinbrecher et al., 2015), and feedback (Glowacki \& Hackman, 2016; Lochmiller, 2016). Although school administrators are tasked with evaluating special education teachers, many do not have a background in special education (Hackman \& Glowacki, 2016; Lawson \& Knollman, 2017; Rodl et al., 2018) and may lack knowledge regarding evidence-based practices for teaching students with disabilities (Bays \& Crockett, 2007; Holdheide et al., 2010; Jacobs et al., 2004; Steinbrecher et al., 2015; Westling et al., 2006). Lacking essential knowledge regarding evidence-based instructional practices could result in inaccurate assumptions about the effectiveness of special education teachers (Correa \&Wagner 2011; Steinbrecher et al. 2015), which could, in turn, result in ineffective special educators remaining in the classroom, exemplary special education teachers not being recognized, or special education teachers generally unable to obtain needed professional development.

Extant research suggests that administrators receive little to no training on special education teacher evaluation in their preparation programs, and, therefore, would benefit from increased opportunities for professional development at their district or school site (Shelton, 2011; Spanneut et al., 2012). Research also suggests that administrators without a special education background do not feel as confident evaluating special education teachers as general education teachers (Glowack \& Hackman, 2016; Rodl et al., 2018), which furthers the need for exploration into the types and quantity of district training that may increase their overall confidence and efficacy in performing their job duties related to evaluation.

The purpose of this study was to explore training and support school administrators identified as needed and that may influence their confidence in performing special education teacher evaluations. First, we were interested in examining the extent to which the amount of district training provided - when it was provided - increased administrator confidence in evaluating special education teachers. Second, we were interested in exploring whether administrators with and without special education teaching credentials differed in the type of training and support needed. This would allow us to determine whether school districts need to focus their training efforts in different areas depending on administrator background, and the types of support specifically required of the majority of administrators who do not have a background in special education.

Finally, we were interested in understanding whether having a background in special education increased administrator confidence in performing teacher evaluations in general. This research aim was exploratory, as there is currently no research in this area, but we hypothesized that school administrators with a special education teacher credential would understand the breadth of student learning types and pedagogical strategies for addressing a variety of learning needs. Consequently, administrators with a special education background may feel more confident evaluating teachers in a range of instructional contexts. This study addressed the following research questions: (a) when controlling for years of experience evaluating special education teachers, to what extent does the amount of district training administrators receive influence their confidence in performing observations and evaluations of special education teachers, (b) do administrators who have never held a special education teaching credential and administrators who have held a special education teacher credential differ in the type of support requested, and (c) when controlling for years of experience evaluating all teachers, to what extent does possessing a special education teaching credential influence administrator confidence evaluating both special education and general education teachers?

\section{METHODS}

\section{Participants}

Between April and May of 2017, 929 school administrators in California completed a survey as part of a larger study on administrators' training and support needs related to evaluating special education teachers (Rodl et al., 2018). Data for the current study were drawn from the larger sample of 929 participants; secondary data analysis was performed 
on item responses that answered this study's research questions. Respondents were recruited through California Department of Education's publicly accessible database, and participants were eligible to complete the survey if they were responsible for formally evaluating teachers in any capacity.

This study included 838 respondents who provided complete data on relevant item responses. Of the 838 administrators in the sample, $89 \%$ were principals or charter school directors, $7.1 \%$ were district level leaders, and $3.9 \%$ were assistant/vice principals or deans. A majority of respondents were the primary school leaders in an elementary school setting (52\%), 18\% were administrators in a high school setting, 16\% were in a middle/junior high school setting, and $14 \%$ were school leaders in other educational contexts (e.g., county-level programs, K-12 setting). A majority of the participants $(88 \%)$ stated that they had never possessed a special education teaching credential, and the remaining $12 \%$ of participants reported holding a special education teaching credential presently or in the past. The school administrators' years of experience evaluating general education teachers ranged from 0 years to 39 years $(\bar{X}=10.61, S D=6.68)$, and their years of experience evaluating special education teachers ranged from 0 years to 39 years $(\bar{X}=9.77, S D=6.72)$.

\section{Survey Instrument}

The original survey included demographic questions related to participants' current assignment, years of experience evaluating general and special education teachers, and credentials held. The survey asked participants to report information about the teacher evaluation system in their school or district, the training they had received in both their personnel preparation programs and their districts related to evaluating teachers generally, and training received related specifically to evaluating special education teachers. Participants were also asked to report their feelings of confidence evaluating both general and special education teachers, and any additional training and supports needed. The survey included a total of 26 items; information regarding instrument development can be found in Rodl et al. (2018).

To answer this study's research questions, the following eight items were included in this secondary analysis: (a) the participant's current assignment (e.g., principal, assistant principal, district-level administrator), (b) whether the participant possessed a special education teaching credential at any point in his or her career, (c) participant's self-reported feelings of confidence evaluating special education teachers (on a 5-point scale from not at all confident to extremely confident), (d) participant's self-reported feelings of confidence evaluating general education teachers (on a 5-point scale from not at all confident to extremely confident) (e) participant's self-reported number of years of experience evaluating special education teachers, (f) participant's self-reported number of years of experience evaluating general education teachers, $(\mathrm{g})$ participant's self-reported number of days of training provided by their districts related to evaluating special education teachers, and (h) whether the participant felt he or she needed more support from the district related to special education teacher evaluation.

\section{Procedure}

During the larger study, potential respondents were emailed an anonymous link to complete the 26-item survey via Qualtrics. The email included information about the study and informed potential respondents that the first 50 participants would receive a $\$ 10$ Amazon gift card for their participation. Respondents who clicked on the link were directed to the implied consent page, and then to the 26 study items. At the end of the survey, participants were redirected to a URL that allowed them to enter their email address if they wished to receive the $\$ 10$ Amazon gift card. The email addresses were not attached to the data; no personally identifying information was collected from the participants. The survey link remained open during a four-week period from April 2017 to May 2017.

\section{Data Analysis}

To answer this study's first research question, which examined the effect of amount of district training received on administrator confidence, a multiple regression using ordinal variables was conducted. The dependent variable was administrators' confidence in performing special education teacher evaluations, reported on a scale from 0 (not at all confident) to 4 (extremely confident). The independent variable was amount of district training, operationalized as the number of days of training provided by the district related to evaluating special education teachers. The independent variables included three dummy variables: less than $1 / 2$ day, $1 / 2$ day to 1 day, and 2 or more days, with no days used as the control. The original survey item allowed for a "more than 3 days" option, but only four participants selected that option; consequently, the " 2 to 3 days" and "more than 3 days" response categories were collapsed into one category of " 2 or more days." Prior research indicates that an increase in years of experience is related to an increase in confidence in 
performing teacher evaluations (Rodl et al., 2018); therefore, years of experience evaluating special education teachers was included in the regression model as a control variable. Heteroskedasticity was detected with the "confidence evaluating special education teacher" variable, as the variability of the studentized residuals was unequal across the range of the predicted linear values; consequently, robust standard errors were used for this multiple linear regression to ensure that the standard errors were not underestimated, thus controlling for non-constant variance.

To investigate the second research question, four tests of proportions using $z$-tests were conducted to determine if credential type was a predictor of the type of support administrators reported needing. The test of proportion $z$-tests were selected to determine whether the two groups (i.e., administrators who had held a special education credential and administrators who had never held a special education credential) differed significantly on four categorical variables: support needed (yes or no), need for professional development (yes or no), need for input from a special education teacher (yes or no), and need for consultation with a special education administrator (yes or no). Respondents could select more than one type of support needed from the response options.

Lastly, to answer the third research question related to the influence of a special education teaching credential on confidence evaluating all teachers, a multiple regression was conducted. The dependent variable, confidence evaluating all teachers, was operationalized as the sum of two variables: confidence evaluating special education teachers (on a 5-point scale) and confidence evaluating general education teachers (on a 5-point scale). The independent variable was possession of a special education teaching credential at any point during the administrator's career and had two levels: yes (possessed a special education teaching credential; coded as 0 ) and no (never possessed a special education teaching credential; coded as 1). Years of experience evaluating all teachers was included in the analysis as a control variable; this variable was created by summing the continuous variables of years of experience evaluating special education teachers and years of experience evaluating general education teachers. Heteroskedasticity was detected with the "total confidence" variable, as the variability of the studentized residuals was unequal across the range of the predicted linear values. As with the analysis for the first research question, robust standard errors were used to ensure that the standard errors were not overestimated.

\section{RESULTS}

A multiple regression was conducted to examine the effect of amount of district training on administrator confidence; a total $R^{2}$ of .14 was found, which was statistically significant $(F(4,833)=32.99, p<.001)$. As shown in Table 1 , after controlling for years of experience evaluating special education teachers, administrators who received less than one half day of training $(n=138)$ related to special education teacher evaluation from their school district felt an estimated 0.15 points higher, on average, in their confidence evaluating special education teachers than administrators who received no training $(n=628),(t=2.06 ; p<.05)$; administrators who received $1 / 2$ to 1 day of training $(n=58)$ felt an estimated 0.39 points more confident than their peers who received no training $(t=3.88, p<.001)$; and administrators who received 2 or more days $(n=14)$ felt an estimated 0.52 points more confident than administrators who received no training $(t=2.75 ; p$ $<.01)$.

Table 1

\section{Summary of Multiple Regression Analysis Predicting Administrator Confidence When Evaluating Special Education Teachers and Amount of District Training $(n=833)$ Using Robust Standard Error}

\begin{tabular}{lccc}
\hline \multicolumn{1}{c}{ District SPED Training } & $\mathrm{B}$ & $S E$ B & $t$ \\
\hline Less than $1 / 2$ day & 0.15 & 0.07 & $2.06^{*}$ \\
$1 / 2-1$ day & 0.40 & 0.10 & $3.88^{* *}$ \\
$2+$ days & 0.53 & 0.19 & $2.75^{*}$ \\
$R^{2}$ & & & .14 \\
$F$ & & & 32.99 \\
\hline$* p<.05 .{ }^{* *} p<.01$ & & &
\end{tabular}


Four tests of proportion $z$-tests were conducted to determine if administrators who have never held a special education teaching credential $(n=738)$ and administrators who have held a special education teacher credential $(n=100)$ differed in the type of support requested. First, a $z$-test was conducted to compare the two administrator groups on whether they needed more support related to special education evaluation. The proportion of administrators without a special education credential who reported wanting more support $(\hat{p}=.64, S D=.02)$ was significantly higher than the proportion of administrators with a special education credential who reported wanting more support $(\hat{p}=.44, S E=.05)\left(z_{(836)}=3.79\right.$, $p<.001)$ results can be seen in Figure 1.

\section{Figure 1}

\section{Administrators' Relative Want of Additional Support for Special Education Evaluations}
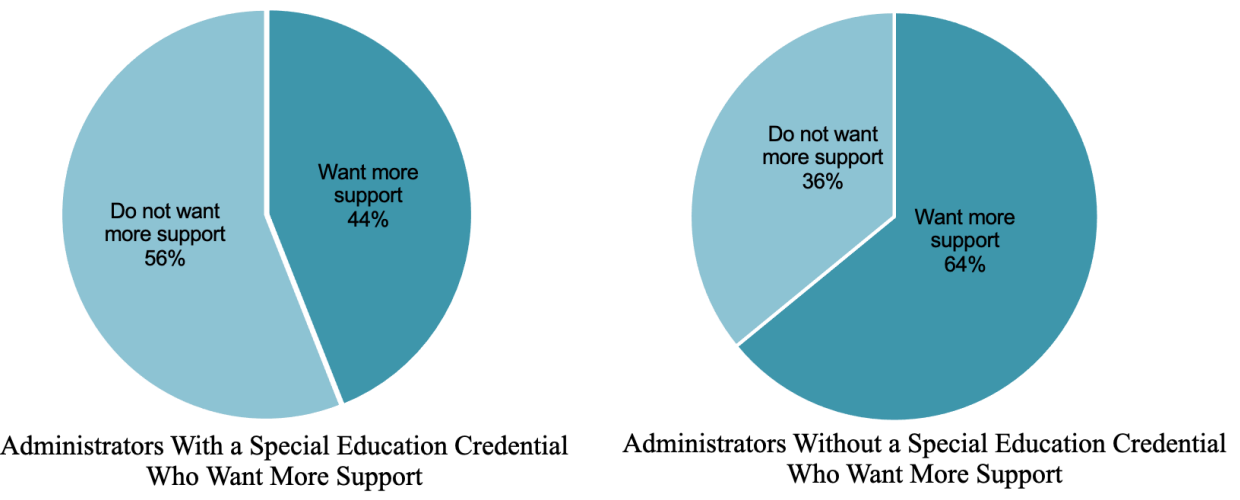

Next, three $z$-tests were conducted to determine if the type of support requested differed between the two groups of administrators (i.e., those with and without a special education credential) for those administrators who reported wanting more support. Results indicated that there was no significant difference between the proportion of administrators without a special education credential who wanted professional development regarding special education teacher evaluation $(\hat{p}=.82, S D=.02)$ and the proportion of administrators with special education credentials who wanted professional development $(\hat{p}=.73, S D=.07)\left(z_{(503)}=1.40, p=.16\right)$. There was also no significant difference between the proportion of administrators without a special education credential wanting consultation with a special education administrator $(\hat{p}=.69, S E=.02)$ and the proportion of administrators with a special education credential who wanted consultation with a special education administrator regarding the evaluation process $(\hat{p}=.61, S D=.01)\left(z_{(503)}=0.96, p=\right.$ .34). In addition, there was no significant difference found between administrators with a general education credential wanting input from a special education teacher concerning the evaluation process $(\hat{p}=.61, S D=.02)$ and administrators with a special education credential $(\hat{p}=.69, S D=.06)\left(z_{(503)}=-1.01, p=.31\right)$.

Lastly, a multiple regression was carried out to investigate the extent to which possessing a special education teaching credential influenced administrator confidence evaluating both special education and general education teachers. The result of the regression indicated that, after controlling for years of experience in teacher evaluation, administrators with a special education credential felt significantly more confident ( 0.47 points higher) than their peers when evaluating both general and special education teachers at their school sites. A total $R^{2}$ of .12 was found, which was statistically significant $(F(2,835)=61.73, p<.001, t=3.75)$.

\section{DISCUSSION}

This study corroborates prior research indicating that there is a need for increased district-provided professional training on special education teacher evaluation (Duncan et al., 2011; Rodl et al., 2018). This is not to say that increased support during preparation programs isn't warranted, but absent formal coursework on special education during preparation programs (Bays \& Crockett, 2007; Bettini et al., 2015; Glowacki \& Hackmann, 2016; Jacobs et al., 2004; Patterson et al., 2000; Steinbrecher et al., 2015; Westling et al., 2006), and little training on special education teacher evaluations specifically (Lawson \& Knollman, 2017), the need for in-service training once school administrators have assumed their professional roles is paramount. In the current study, the more days of training administrators received from their district related to special education evaluation, the more confident they felt evaluating special educators. Though school 
administrators who received 2 or more days of training had a larger coefficient (0.52), showing that they felt significantly more confident than those administrators without any training, it is important to note that those administrators who received a half-day to one-day of training had a similar coefficient (0.39). This suggests that even relatively brief inservice trainings for administrators regarding the special education teacher evaluation process could increase administrator confidence by providing knowledge about a special educator's roles and responsibilities as well as special education best practices. In addition, in-service training could offer an opportunity for administrators to improve their understanding of the evaluation process as a whole and determine any needed modifications to existing evaluation rubrics to better reflect special education teachers' expected teaching skills.

This study is consistent with prior research (Rodl et al. 2018) in that administrators, regardless of their credential type, report wanting increased support regarding special education teacher evaluation. Though administrators with and without special education teaching credentials did not significantly differ in the type of support requested, significantly more administrators without a special education teaching credential wanted more support than their administrator peers who had a special education teaching credential. This indicates that administrators without a special education credential, who typically have a general education background (Bays \& Crockett, 2007), need more support when it comes to special education topics such as evidence-based practices (Holdheide et al., 2010; Steinbrecher et al., 2015), and understanding the multitude of professional roles that special educators assume (Steinbrecher et al., 2015).

Prior research indicates that administrators who have a background in special education feel more confident evaluating special education teachers than their administrator peers who do not have a background in special education, (Rodl et al., 2018), but research has not yet explored whether administrators with a special education background have increased confidence evaluating all teachers. The results of the multiple regression analysis for this study suggest that those administrators who held a special education teaching credential felt significantly more confident evaluating both general and special education teachers at their school sites than administrators who had never held a special education teaching credential. Considering the various roles and responsibilities that special education teachers perform in general education classrooms, such as modifying or accommodating general education curriculum for students with disabilities, co-teaching with general education teachers, and supporting special education students during inclusion or mainstreaming opportunities (McLesky et al., 2017), administrators with a special education background may possess a wider range of knowledge regarding pedagogical strategies for teaching a variety of learners in a variety of settings. It is also possible that administrators with a special education background had also taught in general education settings, which would naturally make them more informed regarding both special and general education teaching. School administrators are not required to have a background in all content levels and grades that they may eventually supervise; for example, a high school principal may have taught English, but evaluates math teachers. It would follow, then, that administrators with a greater variety of prior classroom experiences would feel more confident evaluating and providing teachers with feedback that is specific and relevant. It should be noted that our results are preliminary, and future research should continue to explore how evaluator characteristics and background knowledge impact the observation and evaluation process.

\section{Limitations}

Respondents in this study were limited to California; consequently, we are uncertain whether administrators in other states would have provided the same results. Considering that schools and districts in other geographical locations may use different evaluation assessments, provide various training or professional development opportunities for their administrators, or have different requirements for administrative preparation programs regarding special education courses and teacher evaluation, the results of a nation-wide survey should be used to gain a more comprehensive picture of administrators' knowledge and confidence when it comes to special education teacher evaluation.

As discussed in Rodl et al. (2018), though the sample size is relatively large, the survey had a 9\% response rate. Due to the low response rate, it is difficult to ascertain if those administrators who took part in the survey may fundamentally differ from the principal population who chose not to take the survey leading to response bias. This study is also limited in that it is based on a self-report measure regarding special education teacher evaluation knowledge and confidence. Respondents may not accurately remember the amount or type of training provided to them by their districts or preparation programs, and their reported feelings of confidence may not represent their skill level in performing evaluations. 


\section{Future Directions}

Findings from the current study indicate that one half-day to one-day of training had the most significant effect on administrators' confidence. Consequently, identifying training that is practical and impactful in a limited amount of time is paramount. Research identifying the specific type of training and professional development wanted by administrators with a general or a special education credential regarding modifying an evaluation protocol, observing special education best practices, evaluating, and providing effective feedback to special education teachers should be conducted. A short inservice training could also offer an opportunity for administrators to better understand the special education evaluation system, including assessments and procedures, and identify and implement adjustments to existing evaluation rubrics to better assess their special education teachers.

Future research should examine how raters' characteristics - namely the credential held by the administratorimpacts special education teacher evaluations and the quality of the feedback given. Considering that many administrators with a general education background have little training on special education matters (Bays \& Crockett, 2007; Bettini et al., 2015; Glowacki \& Hackmann, 2016; Jacobs et al., 2004; Patterson et al., 2000; Steinbrecher et al., 2015; Westling et al., 2006) the effectiveness and quality of their feedback may be diminished. However, administrators with a special education credential may provide more direct and cogent feedback to special educators given their former teaching background. Relatedly, future research should explore why administrators with a special education background may feel more confident evaluating both general and special education teachers. Future studies should explore possible characteristics of administrators with special education credentials that may lead them to feel more confident in their evaluation skills.

Finally, this line of research should expand to include rater efficacy rather than just confidence. Research should be conducted to determine if an administrator's confidence, regardless of credential, translates to more effective evaluations and feedback for special education teachers. Specifically, for administrators with special education backgrounds, research should examine whether confidence is correlated with increased skills or abilities related to evaluating both special education and general educators.

\section{REFERENCES}

Angelle, P., \& Bilton, L. M. (2009). Confronting the unknown: Principal preparation training in issues related to special education. AASA Journal of Scholarship \& Practice, 5(4), 5-9.

Bays, D. A., \& Crockett, J. B. (2007). Investigating instructional leadership for special education. Exceptionality, 15, 143161. https://doi.org/10.1080/09362830701503495

Bettini, E., Cheyney, K., Wang, J., \& Leko, C. (2015). Job design: An administrator's guide to supporting and retaining special educators. Intervention in School and Clinic, 50, 221- 225. https://doi.org/10.1177/1053451214532346

Brunsting, N., Sreckovic, M., \& Lane, K. (2014). Special education teacher burnout: A synthesis of research from 1979 to 2013. Education and Treatment of Children, 37, 681-711. https://doi.org/10.1353/etc.2014.0032

Cohen-Vogel, L., \& Harrison, C. (2013). Leading with data: Evidence from the national center on scaling up effective schools. Leadership and Policy in Schools, 12, 122-145. https://doi.org/10.1080/15700763.2013.792934

Correa, V.I., \& Wagner, J.Y. (2011). Principals' roles in supporting the induction of special education teachers. Journal of Special Education Leadership, 24(1), 17- 25.

DiPaola, M. F., \& Walther-Thomas, C. (2003). Principals and special education: The critical role of school leaders (COPPSE Document No. IB-7). Gainesville: University of Florida, Center on Personnel Studies in Special Education.

Duncan, H., Range, B., \& Scherz, S. (2011). From professional preparation to on-the-job development: What do beginning principals need? International Journal of Educational Leadership Preparation, 6(3), 1-20.

Glowacki, H., \& Hackmann, D. G. (2016). The effectiveness of special education teacher evaluation processes: Perspectives from elementary principals. Planning and Changing, 47(3/4), 191-209.

Green, R. L. (2010). The four dimensions of principal leadership: Leading for 21st century schools. Boston, MA: Allyn \& Bacon.

Grissom, J. A., \& Youngs, P. (2016). Making the most of multiple measures. In J. A.

Grissom \& P. Youngs (Eds.), Improving teacher evaluation systems: Making the most of multiple measures (pp. 1-7). New York: Teachers College Press. 
Hess, F. M., \& Kelly, A. P. (2007). Learning to lead: What gets taught in principal-preparation programs. Teachers College Record, 109(1), 244-274.

Hill, H., \& Grossman, P. (2013). Learning from teacher observations: Challenges and opportunities posed by new teacher evaluation systems. Harvard Educational Review, 83, 371-384. https://doi.org/10.17763/haer.83.2.d11511403715u376

Holbrook, A., Krosnick, J. A., \& Pfent, A. (2007). The causes and consequences of response rates in surveys by the news media and government contractor survey research firms. In J. M. Lepkowski, N. C. Tucker, J. M. Brick, E. de Leeuw, L. Japec, P. J., Lavrakas, ...R. L., Sangster (Eds.), Advances in telephone survey methodology (pp. 499528). Hoboken, NJ: John Wiley \& Sons, Inc. https://doi.org/10.1002/9780470173404.ch23

Holdheide, L. R., Goe, L., Croft, A., \& Reschly, D. J. (2010). Challenges in evaluating special education teachers and English Language Learner specialists. [Research and Policy Brief]. National Comprehensive Center for Teacher Quality. http://files.eric.ed.gov/fulltext/ED520726.pdf

Jacobs, J. E., Tonnsen, S., Baker, L. C. (2004). Shaping the role of the principal in special education: What do we know and where do we need to go? AASA Journal of Scholarship \& Practice, 1(1), 7-13

Lawson, J. E., \& Knollman, G. A. (2017). Evaluating special education teachers: School administrators' perceptions of the process. The Journal of Special Education Leadership, 30(1), 6-18.

Lochmiller, C. R. (2016). Examining administrators' instructional feedback to high school math and science teachers. Educational Administration Quarterly, 52, 75-109. https://doi.org/10.1177/0013161X15616660

Lynch, J. (2012). Responsibilities of today's principal: implications for principal preparation programs and principal certification policies. Rural Special Education Quarterly, 31, 40-47. https://doi.org/10.1177/875687051203100205

McLeskey, J., Barringer, M. D., Billingsley, B., Brownell, M., Jackson, D., Kennedy, M., Lewis, T., Ziegler, D. (2017). High-leverage practices in special education. Arlington, VA: Council for Exceptional Children \& CEEDAR Center

Monteith, D. S. (2000). Professional development for administrators in special education:Evaluation of a program for underrepresented personnel. Teacher Education and Special Education, 23, 281-289. https://doi.org/10.1177/088840640002300405

Murphy, J., Hallinger, P., \& Heck, R. H. (2013). Leading via teacher evaluation: The case of the missing clothes? Educational Researcher, 42, 349-354. https://doi.org/10.3102/0013189X13499625

Neumerski, C. M., Crissom, J. A., Goldring, E, Drake, T.A., Rubin, M., Cannata, M., \& Schuermann, P. (2018). Restructuring instructional leadership: How multiple-measure teacher evaluation systems are redefining the role of the school principal. The Elementary School Journal, 119, 270-297. https://doi.org/10.1086/700597

Patterson, J., Bowling, D., \& Marshall, C. (2000). Are principals prepared to manage special education dilemmas? NASSP Bulletin, 84, 9-20. https://doi.org/10.1177/019263650008461303

Rodl, J. E., Bonifay, W., Cruz, R. A., \& Manchanda, S. (2018). A survey of school administrator's training and support related to evaluating special education teachers. Journal of School Administration Research and Development, $3(1), 19-31$.

Shelton, S. V. (2011). Strong leaders, strong schools: 2010 school leadership law. http://www.wallacefoundation.org/knowledge-center/school-leadership/state-policy/Pages/Strong-Leaders-

Strong-Schools-2010-School-Leadership-Laws-.aspx

Spanneut, G., Tobin, J., \& Ayers, S. (2012). Identifying the professional development needs of public school principals based on the interstate school leader licensure consortium standards. NASSP Bulletin, 96, 67-88. https://doi.org/10.1177/0192636512439230

Steinbrecher, T. D., Fix, R., Mahal, S. A., Serna, L., \& McKeown, D. (2015). All you need is patience and flexibility: Administrators' perspectives on special educator knowledge and skills. Journal of Special Education Leadership, $28(2), 89-102$.

Vittek, J. (2015). Promoting special educator teacher retention. SAGE Open, 5, 1-6 https://doi.org/10.1177/2158244015589994

Westling, D., Herzog, M., Cooper-Duffy, K., Prohn, K. \& Ray, M. (2006). The teacher support program: A proposed resource for the special education profession and an initial validation. Remedial and Special Education, 27, 136147. https://doi.org/10.1177/07419325060270030201 
CORRINE M. ARAMBURO, MA, is a graduate student in the special education joint doctorate program at San Francisco State University and the University of California Berkeley. Her primary research interests include administrative leadership in special education, special education administration, examining stigmatization, and applying attribution theory to the organizational practices found in schools and special education classrooms. Email: carambur@sfsu.edu

JANELLE RODL, PhD, is an Assistant Professor of Special Education at San Francisco State University. Her major research interests include special education teacher evaluation, special education teacher preparation, and disproportionality in special education. Email: jrodl@sfsu.edu 